\title{
Epiploic Cystic Lymphangioma Rupture as a Result of Acute Abdomen in a 4-year-old Patient. Case Report
}

\author{
Roberto Pineda-Quiñonez*, R. Uvalle-Villagomez, F. Palacios-Luna, F. Montes-Tapia, J. Rodriguez-Garcia \\ and R. Franco-Marquez \\ Department General Surgery, Autonomous University of Nuevo León, “Dr. José E. González" University Hospital, Nuevo León, Mexico
}

\begin{abstract}
Introduction: Cystic lymphangiomas are rare, benign, and congenital lesions which result from malformations of the lymphatic system. These malformations occur more frequently in pediatric patients, with diverse clinical symptoms. Imaging studies such as ultrasounds, computed tomography scans, and magnetic resonance imaging (MRI) have proven to be of great use in their diagnosis, and with the surgical removal of the lesion being the treatment of choice. Clinical case: A 4-year-old male with a history of hiporexia and early satiety since he was 2 years old. Furthermore, $72 \mathrm{~h}$ before consultation had suffered blunt abdominal trauma, presented tegument paleness and abdominal pain as a result of this trauma. The pain decreased after analgesics. Afterward, there was abdominal distention. We were able to observe a cystic lesion with data gained through an abdominal MRI along with free fluid and active bleeding. During the surgical procedure, a cystic lesion-dependent of the greater omentum is found and verified with a histopathological report. The post-operative evolution of the patient was positive. Conclusion: Abdominal cystic lymphangiomas are rare; the definitive treatment is the removal of the lesion, either with minimally invasive surgery, by laparoscopy or open technique. We ought to have clinical suspicion to offer timely treatment, with the support of imaging studies since clinical presentation varies within the pathology.
\end{abstract}

Key words: Cystic lymphangioma. Greater omentum. Rupture.

\section{Introduction}

Abdominal cystic lymphangiomas are rare, benign, and congenital tumors which result from malformations of the lymphatic system ${ }^{1}$ usually located in the mesentery, followed by the omentum, mesocolon, and retroperitoneum. An epiploic cystic lymphangioma can occur in the greater or lesser omentum and occurs more frequently in pediatric patients (under 10 years of age). Reports show that $60 \%$ of these cases occur in patients under 5 years of age.

Its clinical presentation can be very diverse, from a palpable symptomatic/asymptomatic mass to an acute abdominal mass, which can be life-threatening ${ }^{2}$. Imaging studies are fundamental for its diagnosis since its clinical picture is unspecified. Among the radiological techniques are ultrasounds, CT scans, and/or magnetic resonance imaging (MRIs). The treatment of choice is complete surgical removal.

\section{Case report}

The patient, a 4-year-old male without a significant background (with a history of hiporexia and early satiety since he was 2 years old) began his condition 3 days before his admittance, having suffered blunt abdominal

\section{Correspondence:}

Roberto Pineda-Quiñones

E-mail: drobertop@live.com
Available online: $01-10-2018$ Medicina Universitaria. 2018;20(2):88-90 www.medicinauniversitaria.org

(165-5796/C 2018 Universidad Autónoma de Nuevo León. Published by Permanyer México SA de CV. This is an open access article under the CC BY-NC-ND license (http://creativecommons.org/licenses/by-nc-nd/4.0/). 


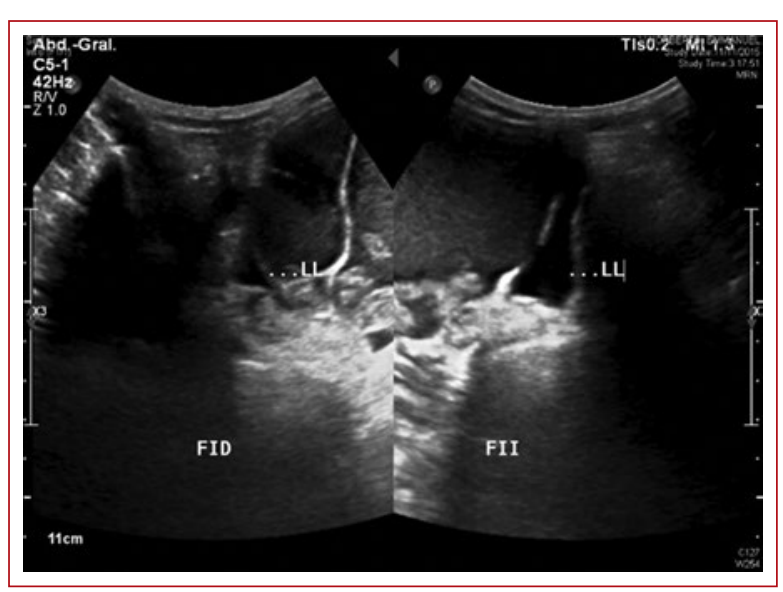

Figure 1. Free fluid in US abdominal image of the right and left iliac fossa

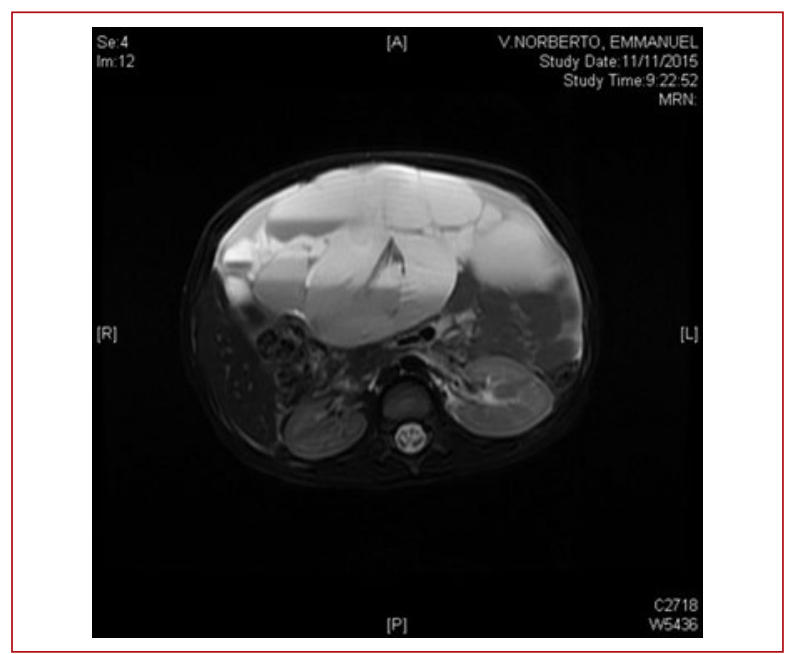

Figure 2. Abdominal magnetic resonance imaging T2 sequence, cross section with septa and liquid-liquid levels.

trauma (a kick). After the first $24 \mathrm{~h}$, he presents as a result of this trauma, tegument paleness, and $48 \mathrm{~h}$ later, moderate abdominal pain with a predominance in the right lower quadrant, which improved with analgesics. On the $3^{\text {rd }}$ day after the trauma, the patient presented abdominal distention with increasing intensity of pain, for this reason, they go to the emergency room at our hospital, with generalized abdominal pain and tachycardia. A thoracoabdominal X-ray is taken showing displacement of bowel loops as well as radiopacity in the anterior compartment. In his pre-operative studies, the patient presents hemoglobin at $7.29 \mathrm{~g} / \mathrm{dL}$ and hematocrit at $21.5 \%$. An abdominal ultrasound was conducted, where we were able to see free fluid in the splenorenal fossa, the right parietocolic gutter, and both iliac fossae

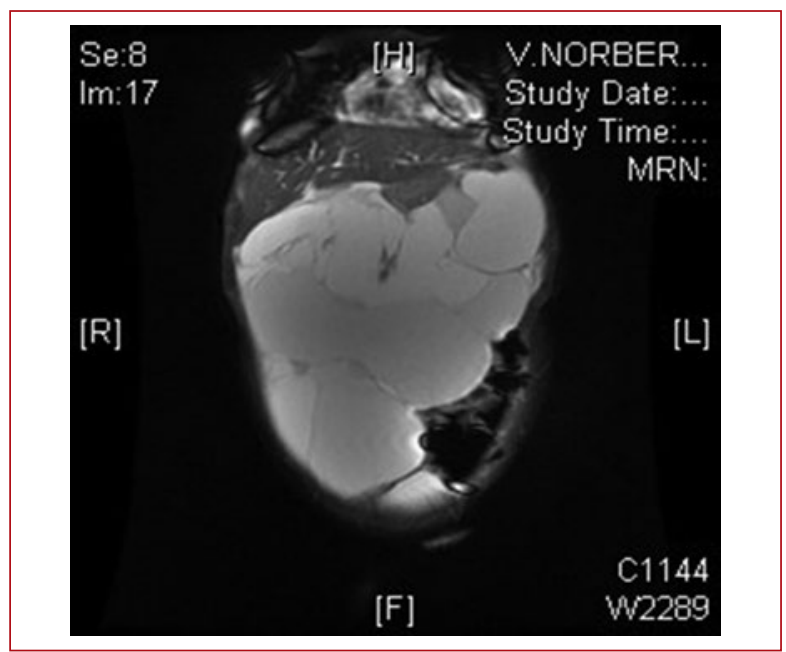

Figure 3. Abdominal magnetic resonance imaging T2 sequence, coronal cut showing multiple septa with liquid.

and the pelvic cavity (Fig. 1). Further studies were conducted with an abdominal MRI, showing a septated multicystic image and hypointense material in the T2 sequence, suggesting a hemorrhage (Figs. 2 and 3). Reanimation of the patient is performed using intravenous fluids. During the surgical approach, $400 \mathrm{cc}$ of hemoperitoneum are found, in addition to an epiploic cyst of approximately $20 \mathrm{~cm} \times 15 \mathrm{~cm} \times 8 \mathrm{~cm}$, ruptured with hematic content inside $(500 \mathrm{cc})$, dependent of the greater omentum (Fig. 4). Cyst removal and omentectomy are performed. An erythrocyte concentrate is transfused in the transoperative. The patient presents a satisfactory evolution and is discharged on day 3 of his post-operative stay. In his histopathological report, we observed cystic lymphangioma, edema, and a recent hemorrhage (Fig. 5).

\section{Discussion}

Cystic lymphangioma is a rare benign tumoral pathology. It may be single, multiple, unilocular, or multilocular, from a few centimeters to $40 \mathrm{~cm}$ in diameter. ${ }^{2}$ In general, located in the subcutaneous tissue in the head, neck, or armpits and can, rarely, be intrabdominal $(2-5 \%){ }^{3}$ It is more common in male pediatric patients, with a reported incidence of approximately 1 in 140,000 patients ${ }^{2}$. Its pathophysiology originates from a malformation in lymph vessels, characterized by dilated cysts of lymphatic content, pus or blood as a result of bleeding ${ }^{4}$. They generally occur in a multiloculated and multiseptated form. Its clinical presentation is very variable, from asymptomatic lesions all the way up to intestinal occlusions, which may occur suddenly. 


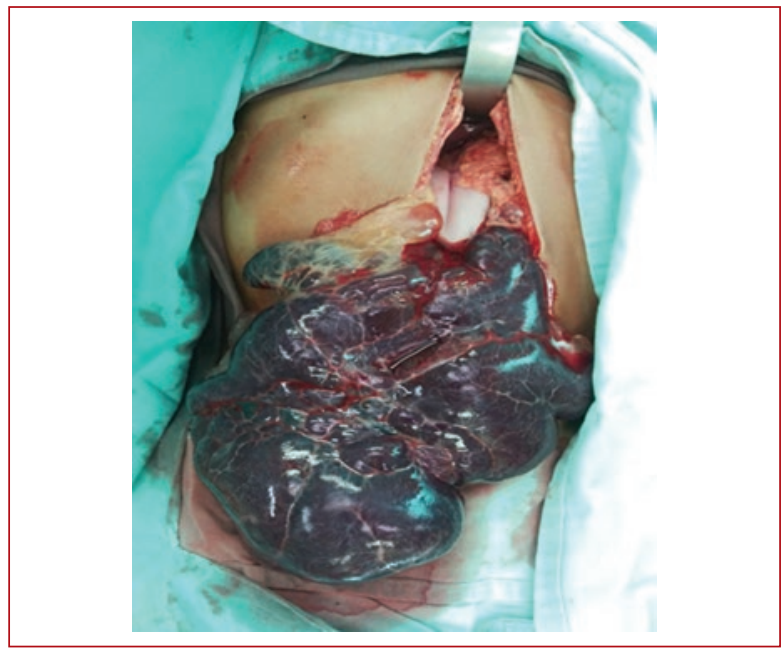

Figure 4. Lymphangioma adhered to omentum before resection

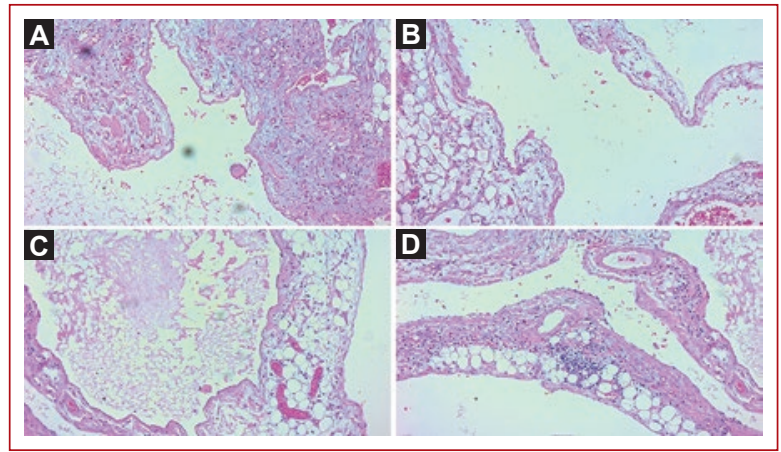

Figure 5. (A-D) Large lymphatic channels containing eosinophilic proteinaceous material are shown in a loose stroma of fibroconnective tissue. Disorganization of the muscular wall can be seen in some foci

Despite the advances in diagnostic techniques, pre-operative diagnosis is a challenge due to its presentation and form, and can sometimes be incidentally discovered when performing a laparotomy procedure or during an autopsy. Ultrasound, tomography, and MRIs are currently valuable tools in the diagnosis of this pathology. There is rarely a recurrence of the tumor following complete surgical removal. A follow-up of the lesion is recommended in the post-operative with an imaging study, an ultrasound being the golden choice.

Within its differential diagnosis of an abdominal cystic mass, there are - cystic teratoma, mucinous cystadenoma, ovarian cysts, bile duct cysts, pancreatic pseudocysts, complicated ascites, renal cysts, and splenic cysts, among others.
Definitive treatment of abdominal cystic lymphangioma involves complete resection. Surgical removal can be conducted using laparoscopic techniques if possi$\mathrm{ble}^{5}$, and lower recurrence rates have been reported in complete removal versus partial removal, aspiration, or sclerosing therapy ${ }^{6}$.

The case we are presenting is interesting since the patient arrived at the emergency room for an assessment with acute abdominal pain (with a background of early satiety and hiporexia. This may very well have been caused by the growth of the lesion) accompanied by signs and symptoms of hypovolemia after the trauma, which lead us to conduct imaging studies to rule out differential diagnoses, and thus obtaining a rare diagnosis.

\section{Conclusion}

Abdominal cystic lymphangioma is rare, definitive treatment is lesion removal, with a rare rate of recurrence. The treatment, while depending on the state of the patient, ought to be in an early manner. The complicated aspect of these cases is the timely diagnosis due to the varied symptomatology.

\section{Ethical disclosures}

Protection of human and animal subjects. The authors declare that no experiments were performed on humans or animals for this study.

Confidentiality of data. The authors declare that they have followed the protocols of their work center on the publication of patient data.

Right to privacy and informed consent. The authors declare that no patient data appear in this article.

\section{References}

1. Takeda $A$, Ito $H$, Nakamura $H$. Large omental cystic lymphangioma masquerading as mucinous ovarian neoplasia in an 8-year-old premenarchal girl: the findings from diagnostic imaging and laparoscopic-assisted excision. J Pediatr Adolesc Gynecol. 2017;30:659-62.

2. Kokhanovsky N, Nachtigal A, Reindorp N, Shinhar D, Zeina AR. Giant omental hemorrhagic cyst presenting as acute hemorrhagic anemia in a 21-month-old infant. Pediatr Emer Care. 2014;30:188-90.

3. Cruz RP, Dalmau LG, Riol YB, Mejias MA. Linfangioma quístico abdominal. A propósito de dos casos pediátricos. Abdominal cystic lymphangioma. Two pediatric cases report. Mediciego. 2010;16 Supl 1:3.

4. Llapur EC, Alvarez JM, Quevedo OP, Lemaur MV, Nesic SP, Urgelles XG. Cystic Lymphangioma as a Cause of Massive Abdominal Hemorrhage. Hindawi Publishing Corporation Case Reports in Critical Care. Vol. 2011. Article ID 492564. p. 2.

5. Leon LG, Samaniego JJ, Lazo BV. Abdomen agudo quirúrgico secundario a Linfangioma quístico abdominal. Rev Med Hered. 2017:28:178-81.

6. Torrealba Al, De Barbieri F. Linfangioma abdominal. Caso clínico. M. Rev Chil Pediatr. 2012;83:68-72. 